“(C) 2019 IEEE. Personal use of this material is permitted. Permission from IEEE must be obtained for all other uses, in any current or future media, including reprinting/republishing this material for advertising or promotional purposes, creating new collective works, for resale or redistribution to servers or lists, or reuse of any copyrighted component of this work in other works." 


\title{
A Trans-Inverse Coupled-Inductor Semi SEPIC DC/DC Converter with Full Control Range
}

\author{
Ali Mostaan, Jing Yuan, Student Member, IEEE, Yam P.Siwakoti, Member, IEEE, Soroush Esmaeili, \\ Frede Blaabjerg, Fellow, IEEE
}

\begin{abstract}
This letter proposes a single switch magnetically coupled dc/dc converter with high voltage gain. The unique features of the converter are summarized as: 1) voltage gain of the converters is raised by lowering its magnetic turn ratio; 2) wide control range $(0<D<1)$; 3) continuous current from the source that makes it a suitable candidate for renewable energy applications; 4) there is no dc current saturation in the core due to the presence of capacitor in the primary winding of the inductor. The feasibility of the proposed converter is studied in details supported by circuit analysis and simulation results. Further, the proposed converter is analyzed and compared with other converters with similar topologies. Finally the superior performance of the circuit is validated experimentally.
\end{abstract}

Index terms - dc-dc converter, SEPIC, coupled inductor, regenerative snubber, voltage stress, renewable energy.

\section{INTRODUCTION}

Renewable energy resources such as Photovoltaic (PV), wind and fuel cell are being widely employed in recent years to decrease the negative side effects due to conventional energy resources. However, the renewable energy resources usually cannot be directly connected to the grid because of their intermittent nature. As an example, the low and variable dcinput voltage (20-45 V) generated from the PV modules should be boosted enough to high voltage (e.g., 200-400 V), in order to generate AC utility voltage using DC/AC converter. Similarly, in hybrid EV (HEV) and other electric traction systems, a voltage of 14 or $42 \mathrm{~V}$ from batteries, fuel cells and/or super capacitors needs to be raised to 200 or $500 \mathrm{~V}$ during various modes of operation [1]. The requirement for dc voltage boosting is even more prominent lately with the emergence of the 400 $\mathrm{V}$ micro-grids powered by multiple energy sources, and the introduction of facility-level $400 \mathrm{~V} \mathrm{DC}$ distribution for data and telecommunication centers. Therefore, high step-up DC/DC converters play a vital role in renewable energy systems $[1,2]$. Conventional boost converters have very simple structures, where its theoretical voltage gain reaches infinitely when the duty cycle is near to unity. Meanwhile, due to higher losses at elevated duty cycle, the practical voltage gain cannot exceed 4-5 even with well designed layout [3]. To overcome this issue of limited voltage gain in the conventional boost converter, different solutions have been presented in the literature [415]. Switch inductor, switch capacitor; multi-cell and cascaded configurations [4-6] are well investigated to achieve higher voltage gain. However, to achieve a high voltage gain several switched inductor/capacitor cells are typically required, resulting in higher cost, size and complexity [7]. Coupled inductor technique is an interesting method to achieve high voltage gain using less number of components $[8,9]$. Usually in most converters with this technique, the voltage gain can be increased by increasing the coupled inductor turn ration, which may lead to higher cost and size [10]. Moreover, usually an additional snubber circuit is required to dissipate the leakage energy of the coupled inductors, which creates the voltage spike across the switch. This leads to more complex circuit with lower overall efficiency [7]. Recently, a series coupled inductor converters based on impedance-source networks have been introduced such as source [11], Y source [12], improve $\Gamma$-source [13]. In these converters, the voltage gain is increased by lowering the coupled inductor turn ratio, which provides a great advantage in reducing the overall size of the converter for higher voltage gain. However, these converter demands higher voltage rated switch with higher Rdson (equal or higher than the output voltage) resulting in higher power loss. In addition, by lowering the coupled inductor turn ratio, the useful range of duty cycle to achieve practical voltage gain is narrowed down. This results in a very steep voltage gain, which complicate the converter control because of greater sensitivity of the output voltage to the duty cycle [10]. Two trans-inverse converters are presented in [10] and [14] with high voltage gain and much lower voltage stress on the switch, however similar to converters in [11-13] the duty cycle operates in narrow range. A new trans-inverse converter is proposed in [15] where duty cycle can vary between 0 and 1 without very steep voltage gain curve, however its input current has high ripple that makes it inappropriate for PV application, where low input current ripple is preferred. To mitigate the aforementioned problems, a novel trans-inverse converter is presented in this letter with continuous input current with very low ripple magnitude. Its duty cycle variation range is between 0 and 1 without very high steep gain curve. In addition, the voltage stress on the switch is much lower than the output voltage. Further it does not require any external snubber circuit, where the leakage energy is recycled by an built-in regenerative snubber circuit and finally the dc-current saturation of the core is prevented due to the presence of the DC current blocking capacitor in series with one of the transformer windings. This letter is organized as follows: in section II, the converter is analyzed in details in continues conduction mode (CCM). The performance of the 


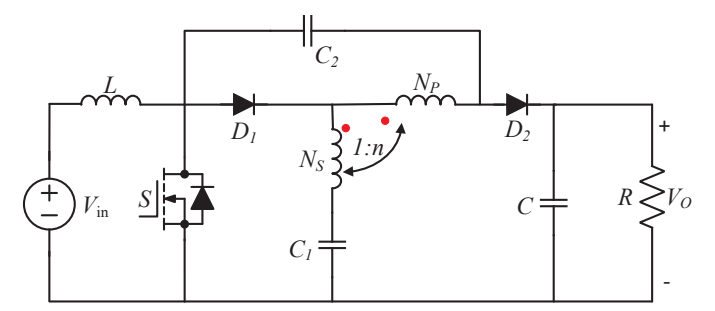

Fig. 1. Schematic of the proposed converter.

converter is verified using simulation and experimental results in section III and the findings drawn are finally concluded in Section IV.

\section{Proposed Trans-Inverse Converter}

\section{A. Description of the converter in CCM}

The schematic of the proposed converter is shown in Fig. 1. Similar to the conventional SEPIC converter, it consists of an input inductor (L), one common ground switch (S), an intermediate capacitor (C2), output diode (D2) and output capacitor (C). With some modification the intermediate inductor in the SEPIC converter is replaced with an impedance network, which consists of one diode (D1), one capacitor (C1) and coupled inductors, where $n=\mathrm{NP} / \mathrm{Ns}$ indicates their turn ratio. To simplify the analysis, the following assumptions are made: 1) All components are ideal that means all equivalent series resistance (ESR) in inductors and capacitors are neglected. In addition the forward voltage drop of the diodes, drain-source on resistance $R_{D S(\mathrm{ON})}$ and parasitic capacitances of the switch (S), are negligible. 2) All capacitors are large enough which the voltage across them is constant in one switching cycle. 3 ) The coefficient of the transformer coupling is one, which means the leakage inductances are zero. However, the leakage inductances effect on the voltage spike across the power switch will be considered in the next subsection. With above assumptions, there are two stages in one switching cycle as shown in Fig. 2. When the power switch turns on as shown in Fig. 2(a), both diodes become reverse bias and turned off. The input inductor charges through the input source and the output load is isolated from the source and is powered by the output capacitor. As it can be seen from Fig. 2(a), we can write:

$$
V_{\mathrm{LM}}=\frac{V_{C 1}-V_{C 2}}{n-1}
$$

Both diodes are forward biased when the switch is turned OFF as shown in Fig. 2(b). The input inductor releases its energy to the load, where its current decreases and the output capacitor is charged from the input source. In this stage the circuit expressions are given as follows:

$$
V_{\mathrm{LM}}=\frac{V_{C 1}-V_{O}}{n-1}
$$

Applying volt-second balance principle to input inductor and magnetizing inductor, they can be obtained as:

$$
D V_{i n}+(1-D)\left(V_{i n}-V_{C 2}-V_{O}\right)=0
$$

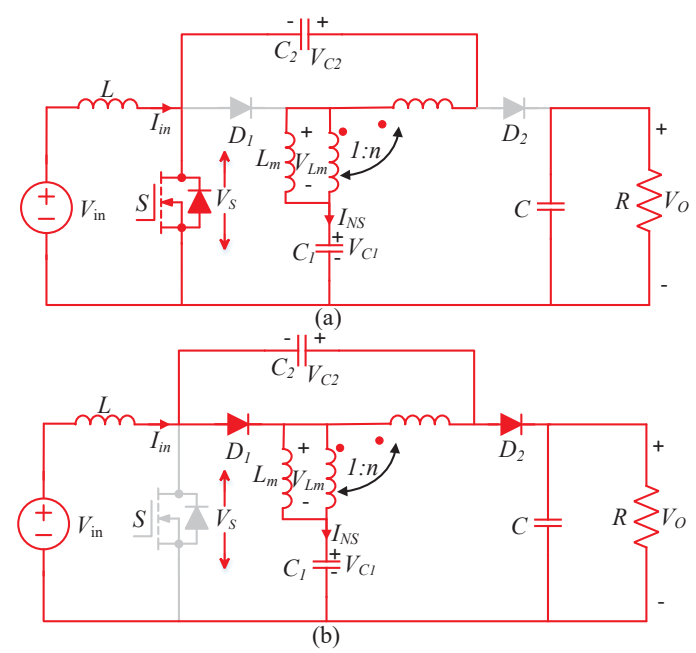

Fig. 2. Equivalent circuits of the proposed converter when the switch turns (a) $\mathrm{ON}$ and (b) OFF.

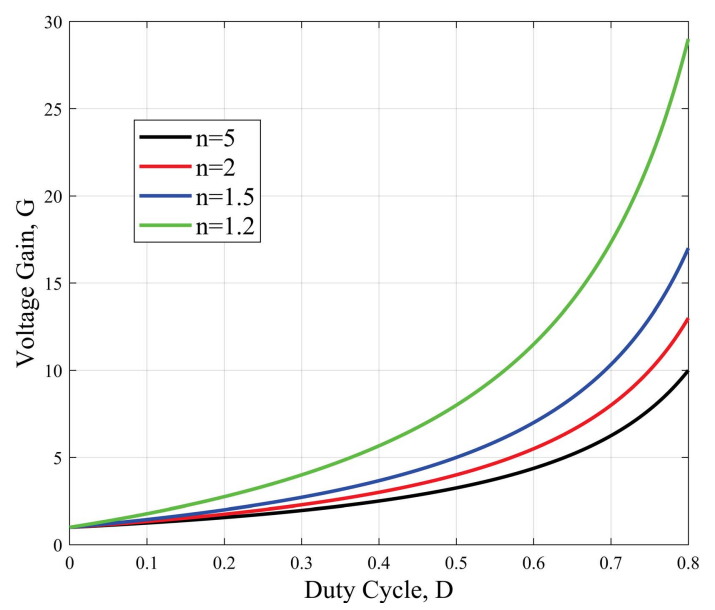

Fig. 3. Voltage gain of the proposed converter in Fig. 1.

$$
D\left(\frac{V_{C 2}-V_{C 1}}{n-1}\right)+(1-D)\left(\frac{V_{C 1}-V_{O}}{n-1}\right)=0
$$

By some derivations, the voltage gain across $C_{1}, C_{2}$ and output voltage are obtained as:

$$
\begin{aligned}
& V_{C 1}=\left(1+\frac{n D /(n-1)}{1-D}\right) V_{\mathrm{in}} \quad V_{C 2}=\left(\frac{n D /(n-1)}{1-D}\right) V_{\mathrm{in}} \\
& V_{O}=G \cdot V_{\mathrm{in}}=\left(\frac{1+n D /(n-1)}{1-D}\right) V_{\mathrm{in}}
\end{aligned}
$$

where $\mathrm{G}$ is the voltage gain of the proposed converter. Refer to (5) and Fig. 3 it is clear that the converter gain increases when the turns ratio decreases. However, the duty cycle range can vary in a wide range $(0<D<1)$, unlike converters presented in [10-13] where the range of duty cycle is narrow.

\section{B. Inbuilt voltage clamp circuit}

In practice, the leakage inductance is nonzero and may cause large voltage spikes on the power switch due to resonance with the switch parasitic capacitor. However, in the proposed 
converter when the power switch is turned OFF, both diodes are turned ON. Refer to Fig. 2(b); the switch voltage is clamped to difference of output voltage and capacitor voltage $V_{C 2}$. Therefore, using capacitors $C_{1}, C_{2}$, and diode $D_{1}$ and $D_{2}$ make an inbuilt regenerative snubber circuit that helps to redirect the leakage energy safely to the power capacitors. With this arrangement, the requirement of additional lossy snubber circuit is eliminated.

\section{Comparison with similar topologies}

Table I presents a comparison of the proposed converter with several trans-inverse type converter. - source [11] and Y source [12] have the lowest number of components, however their input current is discontinuous with high ripple magnitude that makes them inappropriate in renewable energy systems. Converters in [10] and [13] have continuous input current with low ripple, but the duty cycle variation range is narrow particularly when $\mathrm{n}$ is tends to unity which complicates the controller design because of higher sensitivity of the output voltage to duty ratio. In addition, the voltage stress on the switch is high and equal to output voltage in the presented converters in [11-13].

The duty cycle can vary in a wide range in the presented in [15], however the input current ripple in this converter is high, therefore an input filter is mandatory in renewable energy systems that makes its structure more complicated. Compared with [15], the input current ripple in the proposed converter is low and also one diode is saved in the proposed converter compared with [15]. Moreover one DC current block capacitor in series with one coupled inductor can prevent from core saturation in the proposed converter. Compared to converters in [10-13] it has wide range of duty cycle variation for any coupled inductor turn ratio and therefore lower sensitivity to D. In addition, it benefits from low voltage stress on switch in compare with [11-13]. Fig. 4 shows the static voltage gain of the proposed converter and presented converters in [10] and [14] for $\mathrm{n}=1.5$. Converters in $[10,11,14]$ have high voltage gain. However, the duty cycle cannot exceed than $1 / 3$ in $[10,11]$ and $1 / 4$ in [14].

Therefore the duty cycle variation range is narrow and voltage gain varies steeply that makes their control more complicated. In addition, some diodes in [10] and [14] conduct in only a small portion of the switching cycle, which results in a reverse recovery problem. In contrast, the voltage gain variation in the proposed converter is smooth that simplifies its control. From the number of components viewpoint, refer to table I, the converters in [10] and [14] have more number of components compared to the proposed converter.

\section{EXPERIMENTAL RESULTS}

In order to verify the theoretical analysis a prototype is built as shown in Fig. 5. The circuit parameters of the proposed converter are listed in Table II. Fig. 6(a) shows the experimental results under $160 \mathrm{~W}$ output power. The output voltage is about $381.3 \mathrm{~V}$ under open loop control. It is clear that the proposed

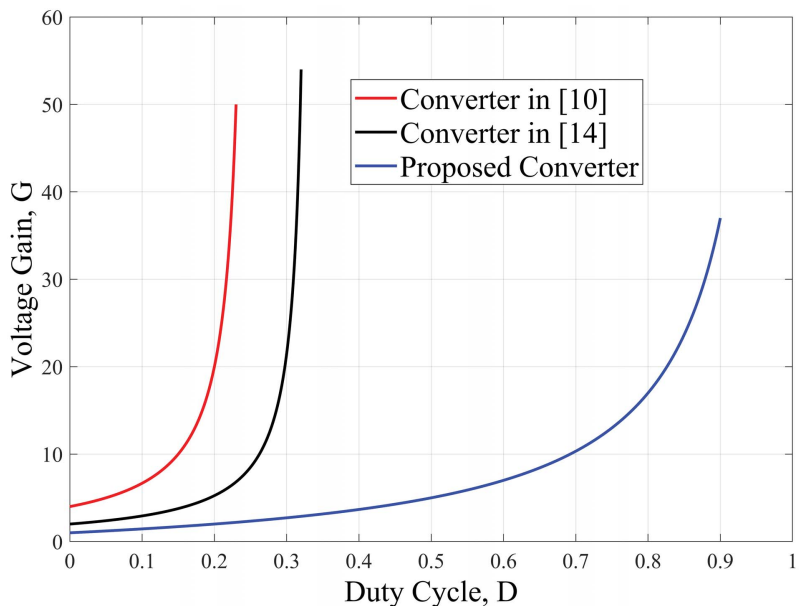

Fig. 4. Voltage gain comparison of the proposed converter and converters in $[10,14]$ for $n=1.5$.

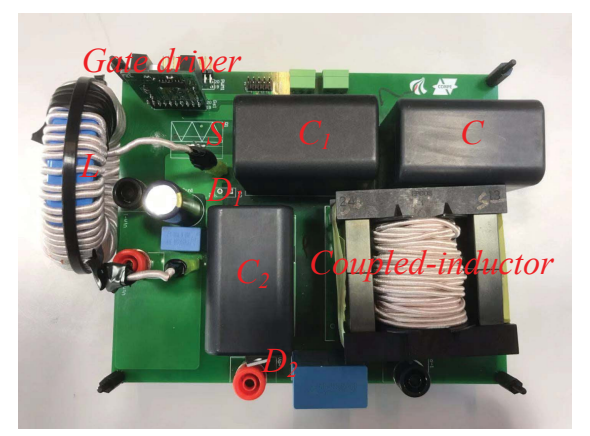

Fig. 5. Picture of the hardware prototype.

converter is able to boost the $48 \mathrm{~V}$ input voltage to higher voltage with acceptable ripple. The input current mean value is $3.5 \mathrm{~A}$. It is obvious that the input current is continuous with low ripple. The input current mean value is $3.5 \mathrm{~A}$ and the input current is continuous with low ripple. The voltage stress on the power switch is about $130 \mathrm{~V}$, that is much lower than the output voltage. It is clear that there is no spike voltage across the power switch that confirms the theoretical analysis. Finally, that figure shows the current that flowing in the transformer secondary winding, it has a periodic signal with no DC current because the capacitor $C_{1}$ in series with transformer winding can prevent from core saturation. Experimental results under output power $320 \mathrm{~W}$ are shown in Fig. 6(b). Under closed loop control the output voltage is about $366 \mathrm{~V}$ because of the more drop voltage on parasitic elements. The input current is continuous and its mean value is about $6.49 \mathrm{~A}$. The effect of the leakage current on the switch voltage is more in this case. However, the voltage spike on the switch is about $70 \mathrm{~V}$, that is lower than voltage stress on switch. Therefore, no snubber circuit is required.

\section{Conclusions}

A new coupled inductor based Semi SEPIC converter is introduced in this letter. The voltage gain of the converter 
TABLE I

COMPARISON WITH STATE OF THE ART TOPOLOGIES.

\begin{tabular}{|c|c|c|c|c|c|c|c|}
\hline Converter & {$[10]$} & [11] & {$[12]$} & [13] & {$[14]$} & {$[15]$} & Proposed \\
\hline $\begin{array}{l}\text { Num. of inductors+ } \\
\text { couple inductors }\end{array}$ & $1+2$ & $0+2$ & $0+3$ & $1+2$ & $1+2$ & $0+2$ & $1+2$ \\
\hline Num. of capacitors & 5 & 2 & 2 & 3 & 5 & 3 & 3 \\
\hline Num. of switches & 1 & 1 & 1 & 1 & 1 & 1 & 1 \\
\hline Num. of diodes & 4 & 2 & 2 & 2 & 4 & 3 & 2 \\
\hline Input current ripple & low & high & high & low & low & high & low \\
\hline DC current block capacitor & yes & yes & yes & yes & no & no & yes \\
\hline Switch voltage stress $\left(\frac{v_{s}}{v_{o}}\right)$ & $\frac{n-1}{2(n-1)+D}$ & 1 & 1 & 1 & $\frac{n-1}{2 n-1}$ & $\frac{n-1}{2 n-1}$ & $\frac{n-1}{2 n-1}$ \\
\hline Duty cycle variation range & $0<D<\frac{n-1}{n}$ & $0<D<\frac{1}{1+\frac{1}{n+1}}$ & $0<D<\frac{1}{k}$ & $0<D<\frac{1}{2+\frac{1}{n+1}}$ & $0<D<\frac{n-1}{2 n-1}$ & $\begin{array}{c}2 n-1 \\
0<D<1\end{array}$ & $\begin{array}{c}2 n-1 \\
0<D<1\end{array}$ \\
\hline
\end{tabular}

TABLE II

DESIGN PARAMETERS OF THE PROPOSED CONVERTER.

\begin{tabular}{cc}
\hline Parameter/Decription & Value/Part Number \\
\hline Power rating & $150-400 \mathrm{~W}$ \\
Input/Output voltage & $48 / 400 \mathrm{~V}$ \\
Capacitor/input inductance & $100 \mu \mathrm{F} / 640 \mu \mathrm{H}$ \\
Turn ratio & $28: 20$ Core:B66397G0000X197 \\
Leakage/magnetizing inductance & $1.27 / 220 \mu \mathrm{H}$ \\
Switching frequency & $100 \mathrm{kHz}$ \\
Duty Cycle & 0.62 \\
Switch S & IPP60R099C6XKSA1 \\
Diode D1\&D2 & IDP30E65D2XKSA1 \\
\hline
\end{tabular}

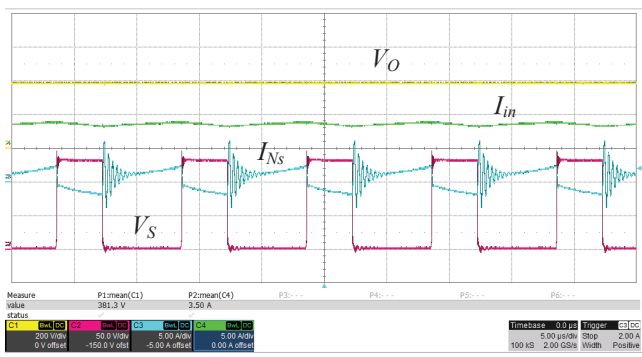

(a)

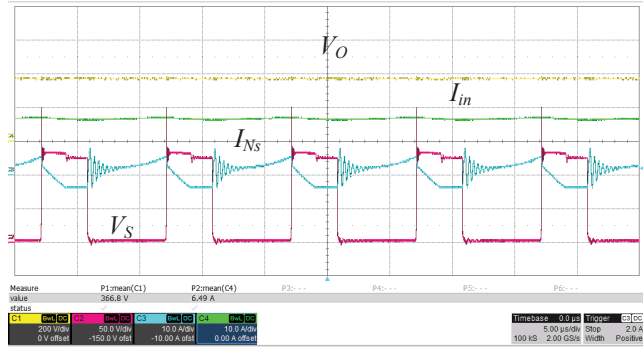

(b)

Fig. 6. Experimental results obtained at (a) Po: $160 \mathrm{~W}$ (b) Po: $320 \mathrm{~W}$ : Output voltage $(200 \mathrm{~V} / \mathrm{div})$, Input current $(5 \mathrm{~A} / \mathrm{div})$, Switch voltage $(50 \mathrm{~V} / \mathrm{div})$ and coupled inductor secondary current $(5 \mathrm{~A} / \mathrm{div})$.

increases by lowering the coupled inductors turn ratio, which may lead to lower size and cost. Unlike most trans-inverse type converters the duty cycle in the proposed converter can vary in wide range, which simplifies the controller design. In addition, the converter draws a continuous current from the source with low ripple magnitude that makes it suitable for renewable energy applications. In addition, a dc blocking capacitor in series with coupled inductor can prevent from core saturation. These demonstrated performances clearly stands out the proposed topology as a competitive alternative for a practical application where a high voltage gain is demanded, such as for fuel cells and PVs.

\section{REFERENCES}

[1] W. Li and X. He, "Review of nonisolated high-step-up DC/DC converters in photovoltaic grid-connected applications," IEEE Trans. Ind. Electron., vol. 58, no. 4, pp. 1239-1250, Apr. 2011.

[2] F. Blaabjerg, , and S. B. Kjaer, "Power electronics as efficient interface in dispersed power generation systems," IEEE Trans Power Electron, vol. 19, no. 5, pp. 1184-1194, Sep. 2004.

[3] A. Mostaan, A. Abdelhakim, M. Soltani, and F. Blaabjerg, "A switchedboost DC/DC converter with high voltage gain and continuous input current," in Proc. 2018 APEC, Mar. 2018, pp. 1540-1545.

[4] B. Axelrod, Y. Berkovich, and A. Ioinovici, "Switchedcapacitor/switched-inductor structures for getting transformerless hybrid DC-DC PWM converters," IEEE Trans. Circuits Syst. I, vol. 55, no. 2, pp. 687-696, Mar. 2008.

[5] Y. Tang, D. Fu, T. Wang, and Z. Xu, "Hybrid switched-inductor converters for high step-up conversion," IEEE Trans. Ind. Electron., vol. 62, no. 3 , pp. 1480-1490, Mar. 2015.

[6] F. L. Tofoli, D. de Souza Oliveira, R. P. Torrico-Bascop, and Y. J. A. Alcazar, "Novel nonisolated high-voltage gain DC-DC converters based on 3SSC and VMC," IEEE Trans. Power Electron., vol. 27, no. 9, pp. 3897-3907, Sep. 2012.

[7] Y. P. Siwakoti, A. Mostaan, A. Abdelhakim, P. Davari, M. Soltani, M. N. H. Khan, L. Li, and F. Blaabjerg, "High voltage gain quasi-SEPIC DC-DC converter," IEEE J. Emerg. Sel. Top. Power Electron., pp. 1-1, 2018.

[8] J. Yao, A. Abramovitz, and K. M. Smedley, "Analysis and design of charge pump-assisted high step-up tapped inductor SEPIC converter with an inductorless regenerative snubber," IEEE Trans. Power Electron., vol. 30 , no. 10 , pp. 5565-5580, Oct. 2015.

[9] K. Tseng, J. Lin, and C. Huang, "High step-up converter with threewinding coupled inductor for fuel cell energy source applications," IEEE Trans. Power Electron., vol. 30, no. 2, pp. 574-581, Feb. 2015.

[10] Y. P. Siwakoti, F. Blaabjerg, and P. Chiang Loh, "High step-up transinverse $\left(T x^{-1}\right)$ DC-DC converter for the distributed generation system," IEEE Trans. Ind. Electron., vol. 63, no. 7, pp. 4278-4291, Jul. 2016.

[11] P. C. Loh, D. Li, and F. Blaabjerg, " $\Gamma$-Z-source inverters," IEEE Trans. Power Electron., vol. 28, no. 11, pp. 4880-4884, Nov. 2013.

[12] Y. P. Siwakoti, P. C. Loh, F. Blaabjerg, S. J. Andreasen, and G. E. Town, "Y-source boost DC/DC converter for distributed generation," IEEE Trans. Ind. Electron., vol. 62, no. 2, pp. 1059-1069, Feb. 2015.

[13] W. Mo, P. C. Loh, and F. Blaabjerg, "Asymmetrical $\Gamma$-source inverters," IEEE Trans. Ind. Electron., vol. 61, no. 2, pp. 637-647, Feb. 2014.

[14] H. Liu, J. Wang, and Y. Ji, "A novel high step-up coupled-inductor DCDC converter with reduced power device voltage stress," IEEE J. Emerg. Sel. Top. Power Electron., pp. 1-1, 2018.

[15] H. Liu, F. Li, and P. Wheeler, "A family of DC-DC converters deduced from impedance source DC-DC converters for high step-up conversion," IEEE Trans. Ind. Electron., vol. 63, no. 11, pp. 6856-6866, Nov. 2016. 